\title{
$\mathrm{Ka}$ 대역 $50 \mathrm{~W}$ 급 고출력증폭기(SSPA) 설계 및 제작
}

\section{Design and Fabrication of Ka-Band 50-W Class Solid-State Power Amplifier}

\author{
한재섭 · 정주용 · 박성민 · 유경덕 · 김보균 ${ }^{\star} \cdot$ 김효철** \\ Jae-Sub Han · Joo-Yong Jung · Seong-Min Park · Kyung-Deok Yu · Bo-Gyun Kim* $\cdot$ Hyo-Chul Kim** \\ 요 약 \\ 본 논문에서는 레이다, 유도 무기 탐색기 및 위성 탑재용 SAR에 적용할 수 있는 Ka대역 $50 \mathrm{~W}$ 급 고출력증폭기(SSPA) \\ 설계 및 제작 결과에 대해 기술하였다. 단위 증폭기 $(\mathrm{HPA})$ 로는 $10 \mathrm{~W}$ 급 $\mathrm{GaN}$ 소자의 $\mathrm{MMIC}$ 를 적용하였고, 이를 8 개 결합 \\ 하여 $50 \mathrm{~W}$ 이상의 출력으로 증폭할 수 있도록 구성하였다. 전력분배기와 전력결합기는 도파관 Radial 결합기를 개발하여 \\ 삽입 손실을 최소화하였고, 전력분배기와 전력결합기의 삽입 손실은 대역 내 $-0.4 \mathrm{~dB}$ 이하로 제작하였다. $\mathrm{SSPA}$ 는 펄스 \\ 형으로 듀티 $20 \%$ 까지 동작하도록 설계하였고, 송신 출력은 최대 듀티에서 대역 내 최소 $75 \mathrm{~W}$ 이상이며, 송신 효율은 \\ DC-DC 변환기 및 구동증폭모듈을 포함하여 $12.3 \%$ 이상이다. 단위 증폭기의 운용 온도를 낮추기 위해 하우징은 $\mathrm{CuW}$ 를 \\ 적용하였고, 상온에서 별도의 냉각 장치 없이 5 분 운용 시에 $\mathrm{HPA}$ 의 바닥면 온도는 최고 62.4 도 이하임을 확인하였다.
}

\section{Abstract}

This paper presents a 50-W class solid-state power amplifier (SSPA) operating in the Ka-band for use in radar, seeker, and synthetic aperture radar applications. We first designed a unit high-power amplifier (HPA) module utilizing a 10-W class monolithic microwave integrated circuit based on GaN technology and then combined eight of these HPA modules to generate more than $50 \mathrm{~W}$ of output power. A waveguide radial combiner was developed to combine all the HPAs such that the insertion loss was minimized; the measured insertion loss of the waveguide radial combiner was less than $-0.4 \mathrm{~dB}$ within the pass band. The SSPA is designed to operate at a maximum duty cycle of $20 \%$ in the pulsed mode and produces at least $75 \mathrm{~W}$ of output power at maximum duty with an efficiency of $12.3 \%$, including a DC-DC converter and a drive amplifier module. CuW-based housing was introduced for the HPA modules to minimize the temperature of the bottom surface of the HPA, which was measured to reach $62.4{ }^{\circ} \mathrm{C}$ at most without the use of an additional cooling device.

Key words: Ka Band, SSPA, Waveguide Radial Combiner, GaN

$$
\text { I. 서 론 }
$$

최근 레이다나 유도 무기의 탐색기 등의 고출력증폭기 로 TWTA(travelling wave tube amplifier)에서 SSPA(solid

\footnotetext{
「이 논문은 2020년도 정부(과학기술정보통신부)의 재원으로 정보통신기획평가원의 지원을 받아 수행된 연구임 (No.2018-0-01658, 차세대 위성 핵심 기술 개발).」 
state power amplifier)로 바뀌고 있고, 소형 경량화를 하기 위해 $\mathrm{Ka}$ 대역 이상 높은 주파수의 수요가 증가하고 있다. $\mathrm{SSPA}$ 개발은 $\mathrm{GaN}$ 을 이용한 반도체 소자의 개발이 활발 해짐에 따라 더욱 가속화되고 있다. TWTA는 단일 튜브 를 이용하고 고출력/고효율인 장점이 있지만, 튜브 고장 시 장비 운용이 불가하고, 국내 정비가 어려운 단점이 있 다. 또한, 장비 예열 시간으로 수 백초 이상 필요하며, 고 전압을 사용해야 된다는 단점이 있다. 이에 반해 SSPA는 단일 증폭 소자의 출력이 튜브 대비 낮아서 여러 개 소자 의 출력을 결합하여 고출력을 생성하므로 하나의 소자가 동작을 하지 않아도 전체 $\mathrm{SSPA}$ 는 조금 낮은 출력으로 운 용이 가능하다(graceful degradation). 그리고, 국내 수급이 용이하고 광대역에 신뢰도가 높으며, 장비 예열 시간이 길지 않은 장점이 있다 ${ }^{[1],[2]}$.

본 연구에서는 Ka대역 $(35 \sim 36 \mathrm{GHz})$ 의 고출력증폭기 (SSPA) 개발을 위해 종단 $\mathrm{HPA}$ (high power amplifier) 모듈 은 $\mathrm{GaN}$ 소자의 $10 \mathrm{~W}$ 급 상용품을 이용하였고, 모듈 8 개를 도파관 형태의 Radial 결합기로 결합하여 $50 \mathrm{~W}$ 이상의 출 력으로 증폭할 수 있도록 제시하였다. 본 연구를 통해 개 발된 SSPA는 임의의 탑재체에 적용하기 위해 $50 \mathrm{~W}$ 이상 의 출력을 내는 것 외에도 전원 보호, 고장 감지, 온도 감 지 및 전류 제한 회로 등을 구성하였지만, 본 논문에서는 $\mathrm{RF}$ 성능 위주로 설계 및 제작 결과를 제시하였다.

\section{II. 본 론}

본 논문의 고출력증폭기는 $\mathrm{Ka}$-대역의 $\mathrm{RF}$ 펄스 신호를 인가 받아 $50 \mathrm{~W}$ 이상 증폭하고, 듀티는 최대 $20 \%$, 펄스 폭은 최대 $100 \mu \mathrm{s}$ 까지 운용 가능하도록 설계하였다. 고 출력증폭기는 구동증폭모듈, 전력결합기/분배기, 종단 $\mathrm{HPA}$ (high power amplifier) 및 전원변환모듈 등으로 구성되어 있다. $\mathrm{HPA}$ 는 $\mathrm{GaN}$ 소자의 $10 \mathrm{~W}$ 급 상용 부품을 이용하였 고, 전력결합기와 분배기는 8-Way Radial 도파관 형태의 전력결합기/분배기를 이용하여 구성하였으며, 내부 제작 사진은 그림 1 과 같고, 크기와 형상은 그림 2 와 같다.

\section{2-1 고출력증폭기 구성 및 기능}

고출력증폭기는 그림 3 과 같이 $+28 \mathrm{~V}$ 의 전원을 인가받

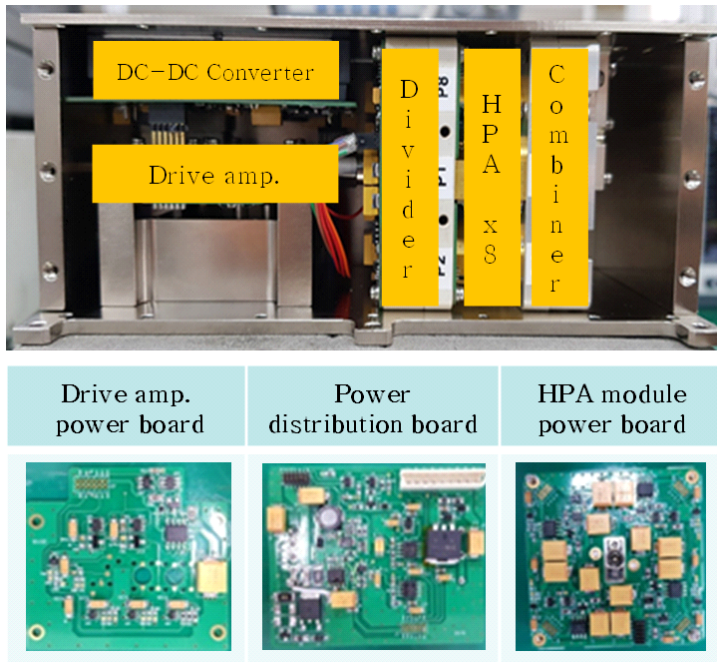

그림 1. 고출력증폭기(SSPA) 제작 사진

Fig. 1. Photograph of the SSPA.

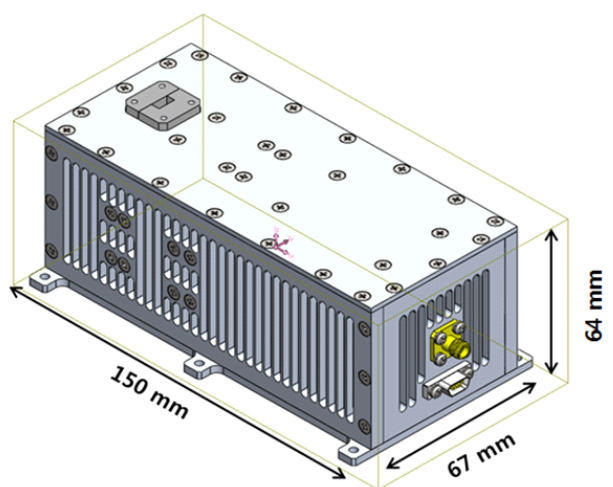

그림 2. 고출력증폭기(SSPA) 형상

Fig. 2. Shape of the SSPA.

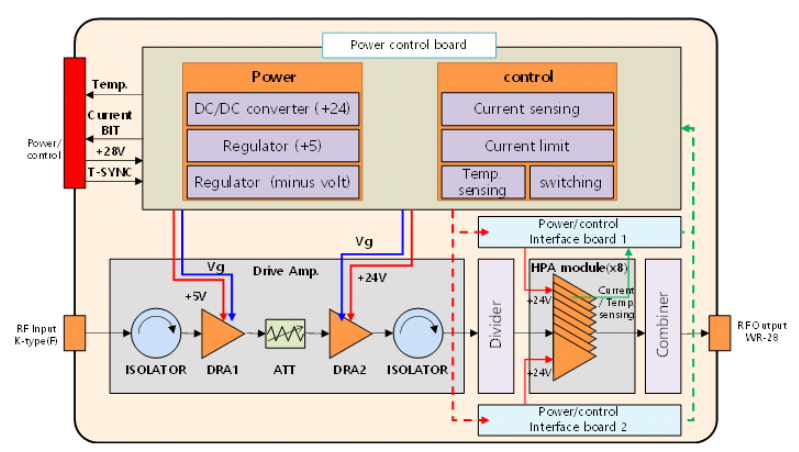

그림 3. 고출력증폭기(SSPA) 기능블럭도

Fig. 3. Functional block diagram of SSPA. 
THE JOURNAL OF KOREAN INSTITUTE OF ELECTROMAGNETIC ENGINEERING AND SCIENCE. vol. 32, no. 1, January. 2021.

아 내부의 필요한 전원 $+24 \mathrm{~V},+5 \mathrm{~V}$ 및 음전원을 생성 한다. 그리고, 효율을 향상시키기 위해 펄스가 인가되는 구간에만 바이어스가 인가되도록 스위칭 회로를 구성하 였다. 스위칭 회로는 외부로부터 TTL(transistor-transistor $\operatorname{logic}$ ) 신호를 인가받아 동작하고, $+24 \mathrm{~V}$ 의 드레인 전원이 스위칭되도록 설계하였으며, 효율을 높이기 위해 $+24 \mathrm{~V}$ 의 상승 시간과 하강 시간이 최소화되도록 설계하였다. $+24 \mathrm{~V}$ 전원 생성은 DC-DC 변환기를 이용하였고, 그 외 전원은 전압 레귤레이터를 이용하여 생성하였다. $+28 \mathrm{~V}$ 전원 입력단에는 돌입 전류 제한 회로를 구성하여 초기 전원 인가 시 과전류로 인한 고장을 보호하도록 하였다.

고출력증폭기는 RF 입력 신호의 주파수 평탄도가 낮 거나 흔들리더라도 송신 출력이 일정할 수 있도록 초단 DRA1을 포화상태가 되도록 구성하였다. 또한, 결합분배 기 입력 반사 손실에 의한 HPA1의 발진과 특성 변화를 최소화하기 위해 아이솔레이터를 배치하였다. 고출력증 폭기의 $\mathrm{RF}$ 버짓은 표 1 과 같다.

표 1. 고출력증폭기(SSPA) 버짓

Table 1. Budget of the SSPA.

\begin{tabular}{|c|c|c|c|c|}
\hline Item & $\begin{array}{c}\text { Gain } \\
(\mathrm{dB})\end{array}$ & $\begin{array}{c}\text { Output } \\
(\mathrm{dBm})\end{array}$ & $\begin{array}{c}\text { Output } \\
(\mathrm{W})\end{array}$ & Remark \\
\hline RF input & & 12.5 & 0.0 & \\
\hline K-connector & -1 & 11.5 & 0.0 & \\
\hline Isolator & -1 & 10.5 & 0.0 & \\
\hline Attenuator & -6 & 4.5 & 0.0 & \\
\hline DRA1 & 17 & 17 & 0.1 & Saturation \\
\hline Attenuator & -11 & 6 & 0.0 & \\
\hline DRA2 & 18 & 24 & 0.3 & \\
\hline Attenuator & 0 & 24 & 0.3 & \\
\hline HPA1 & 14 & 38 & 6.3 & \\
\hline Isolator & -1 & 37 & 5.0 & \\
\hline 8-Way divider & -10 & 27 & 0.5 & $\begin{array}{c}\text { Insertion loss } \\
-1 \mathrm{~dB}\end{array}$ \\
\hline HPA2 & 14 & 40 & 10.0 & Saturation \\
\hline 8-Way combiner & 8.4 & 48.4 & 69.2 & $\begin{array}{c}\text { Insertion loss } \\
-0.6 \mathrm{~dB}\end{array}$ \\
\hline Summary & 41.4 & 48.4 & 69.2 & \\
\hline
\end{tabular}

\section{2-2 단위증폭모듈 제작}

고출력증폭기의 RF 경로는 DRA(drive amplifier), 구동 용 $\mathrm{HPA}$ 및 종단 $\mathrm{HPA}$ 8개로 구성되어 있다. DRA는 Neditek社의 NDAC01059를 적용하였고, 구동용 $\mathrm{HPA}$ 와 종단 $\mathrm{HPA}$ 는 동일 부품으로 Neditek新의 NDAC01025를 적용하여 제작하였다. 두 부품은 모두 $\mathrm{GaN}$ 소자의 증폭 기이다. 그림 4는 DRA의 단품 시험을 위한 치구 제작 사 진이다. DRA칩의 입출력단은 마이크로스트립 라인에 와 이어 본딩으로 연결하였고, $\mathrm{DRA}$ 에 $+11 \mathrm{dBm}$ 정도 입력되 었을 때, 출력은 약 $+25 \mathrm{dBm}$ 까지 증폭하였으며, 그림 5 는 DRA 입력 대비 출력 레벨 측정 결과이다. 구동용 $\mathrm{HPA}$ 는 $\mathrm{DRA}$ 와 완조립하여 측정하였고, 출력은 대역 내 최소 +35 $\mathrm{dBm}$ 이상 증폭하였다.

종단 $\mathrm{HPA}$ 모듈은 고출력증폭기 $50 \mathrm{~W}$ 이상의 출력을 위해 8 개를 제작하였다. $\mathrm{HPA}$ 칩의 입출력단은 마이크로

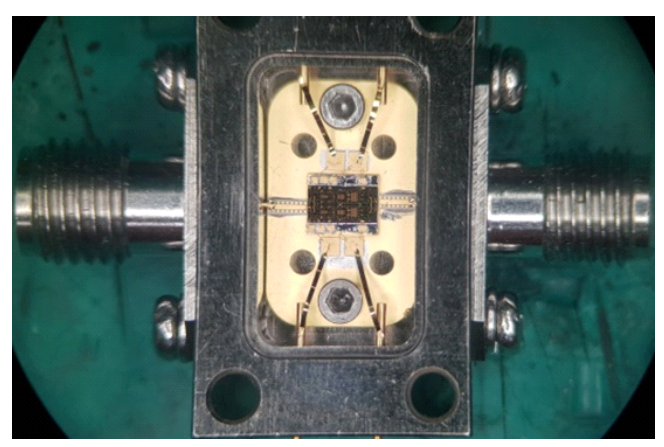

그림 4. DRA 단품 측정 치구 제작 사진

Fig. 4. Photograph of DRA test jig.

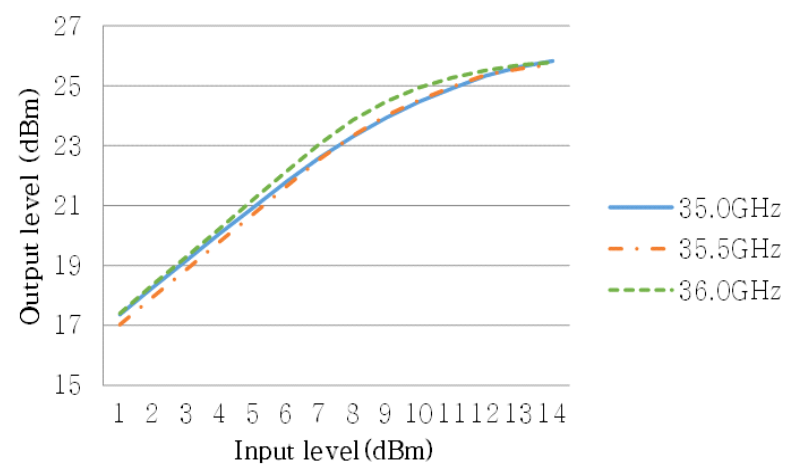

그림 5. DRA 출력 측정 결과

Fig. 5. Measured results of DRA output power. 
스트립 라인에 와이어 본딩으로 연결하였다. 종단 $\mathrm{HPA}$ 모듈의 입출력 $\mathrm{RF}$ 커넥터는 조립성을 향상시키고, $\mathrm{HPA}$ 모듈과 전력결합기/분배기의 방열 경로를 짧게 형성하기 위해 SMP(sub miniature push-on) 커넥터를 이용하였으며, 제작 사진은 그림 6 과 같다. $\mathrm{HPA}$ 의 출력 레벨은 $\mathrm{Idq}$ 를 조 정하여 최대 출력보다 조금 낮더라도 효율이 높게 나오 도록 조정하였다. 종단 $\mathrm{HPA}$ 모듈은 전력 결합 시 $\mathrm{HPA}$ 모 듈 간 진폭과 위상 오차가 적어야 결합 효율이 높은데, 8 개의 $\mathrm{HPA}$ 모듈 측정 결과, 출력 레벨의 차이는 최대 1.5 $\mathrm{dB}$, 위상은 최대 22.3 도의 오차가 있었고, 8 개 $\mathrm{HPA}$ 의 측 정 결과는 표 2와 같다. 표 3은 HPA 모듈 별 효율 및 발열 량을 산출하였다. 상용 $\mathrm{HPA}$ 의 데이터는 효율 $25 \%$ 이었고,

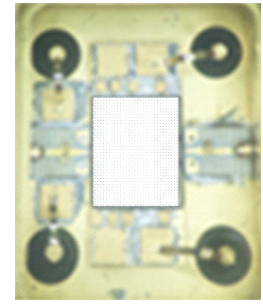

그림 6. 종단 $\mathrm{HPA}$ 모듈 제작 사진

Fig. 6. Photograph of HPA module.

표 2. $\mathrm{HPA}$ 출6력과 위상 측정 결과

Table 2. Measured results of output power and phase for HPA.

\begin{tabular}{|c|c|c|c|c|c|c|}
\hline Item & \multicolumn{2}{|c|}{ Output level $(\mathrm{dBm})$} & \multicolumn{3}{c|}{ Phase (degree) } \\
\hline $\begin{array}{c}\text { Frequency } \\
(\mathrm{GHz})\end{array}$ & 35 & 35.5 & 36 & 35 & 35.5 & 36 \\
\hline No.1 HPA & 40.3 & 40.8 & 40.6 & 106.2 & 33.9 & -25.9 \\
\hline No.2 HPA & 40.7 & 40.5 & 40.3 & 100.9 & 30 & -34.7 \\
\hline No.3 HPA & 41.5 & 41.3 & 40.9 & 106.6 & 33.4 & -31.3 \\
\hline No.4 HPA & 41.2 & 41.2 & 41.2 & 115.6 & 44.4 & -21.4 \\
\hline No.5 HPA & 40.9 & 40.9 & 40.9 & 116.6 & 45.2 & -18.9 \\
\hline No.6 HPA & 41.1 & 41.2 & 41 & 113.9 & 42.1 & -27.2 \\
\hline No.7 HPA & 41.3 & 41.4 & 41.3 & 115.9 & 45.6 & -20.9 \\
\hline No.8 HPA & 40 & 40 & 40.1 & 94.3 & 27.3 & -37.2 \\
\hline Maximum & 41.5 & 41.4 & 41.3 & 116.6 & 45.6 & -18.9 \\
\hline Minimum & 40 & 40 & 40.1 & 94.3 & 27.3 & -37.2 \\
\hline Deviation & 1.5 & 1.4 & 1.2 & 22.3 & 18.3 & 18.3 \\
\hline
\end{tabular}

표 3. $\mathrm{HPA}$ 효율과 발열량 산출 결과

Table 3. Calculated results of efficiency and heating value for HPA.

\begin{tabular}{|c|c|c|c|c|c|c|}
\hline Item & \multicolumn{3}{|c|}{ Efficiency (\%) } & \multicolumn{3}{c|}{ Heating value (W) } \\
\hline $\begin{array}{c}\text { Frequency } \\
(\mathrm{GHz})\end{array}$ & 35 & 35.5 & 36 & 35 & 35.5 & 36 \\
\hline No.1 HPA & 18.5 & 21.0 & 23.1 & 8.7 & 9.5 & 8.8 \\
\hline No.2 HPA & 19.8 & 20.8 & 22.6 & 9.4 & 8.9 & 8.3 \\
\hline No.3 HPA & 22.1 & 23.2 & 24.5 & 11.0 & 10.4 & 9.3 \\
\hline No.4 HPA & 21.2 & 22.2 & 24.8 & 10.4 & 10.3 & 9.9 \\
\hline No.5 HPA & 19.2 & 20.3 & 22.9 & 9.9 & 9.8 & 9.5 \\
\hline No.6 HPA & 21.0 & 22.2 & 20.6 & 10.2 & 10.2 & 10.0 \\
\hline No.7 HPA & 21.6 & 23.2 & 25.1 & 10.6 & 10.6 & 10.1 \\
\hline No.8 HPA & 17.6 & 19.0 & 20.9 & 8.2 & 8.1 & 8.1 \\
\hline MMIC Data & \multicolumn{7}{|c|}{25} & \multicolumn{5}{c}{} \\
\hline
\end{tabular}

$\mathrm{HPA}$ 모듈로 구성 시 효율은 $17.6 \%$ 24.8\%로 측정되었 다. HPA 모듈을 구성할 때 와이어 본딩, $\mathrm{PCB}$ 라인, SMP 커넥터 및 불릿 등이 포함되어 효율이 조금 낮아졌다.

\section{2-3 전력분배기결합기 설계 및 제작}

전력분배기와 전력결합기는 8-Way 도파관 Radial 결합 기 타입으로 선정하였고, 전력분배기의 입력 포트는 K-커 넥터 타입으로 연결할 수 있도록 설계하였으며, 전력결합 기의 결합(출력) 포트는 고출력을 고려하여 WR-28 규격 의 도파관으로 설계하였다. Binary 결합기는 결합 포트 수가 많아질수록 비례하여 손실이 커지고, Radial 결합기 는 결합수가 많아져도 손실이 거의 변화가 없어 8-Way 이상에서는 손실이 작은 장점이 있다. Radial 결합기는 마 주 보는 포트 간 격리도가 최대 $-6 \mathrm{~dB}$ 정도 되는 특성을 가지고 있어 각 증폭기 출력단에 증폭기 보호를 위한 아 이솔레이터를 적용해야 되지만, 최근 절연 파괴 전압 특 성이 높은 $\mathrm{GaN}$ 소자의 증폭기를 적용하면 아이솔레이터 없이 결합구조를 구성할 수 있다.

전력분배기는 입력되는 전력이 크지 않기 때문에 K-커 넥터를 선정하였다. 구동 HPA(HPA1)의 출력이 $10 \mathrm{~W}$ 급 임을 고려하여 정격 전력이 $20 \mathrm{~W}(\mathrm{CW}$ 기준)인 K-커넥터를 선정하였고, 8-Way로 분배되는 커넥터는 전력분배기와의 
조립성 및 짧은 방열 경로를 형성하기 위해 SMP 커넥터 를 선정하였다. SMP 커넥터에서 도파관으로 전력 변환하 는 프로브는 설계 제작하여 적용하였고, 전력을 합성하는 $\mathrm{K}-$ 커넥터부 프로브도 설계 및 제작하였으며, 제작 형상은 그림 7과 같고, 높이는 $25.3 \mathrm{~mm}$ 에 가로/세로 길이는 56 $\mathrm{mm}$ 이며, 시뮬레이션 결과는 그림 8과 같다. 그리고, $\mathrm{SMP}$ 커넥터로 분배되는 각 도파관 경로에는 반사 손실을 개 선하기 위해 튜닝 스크류를 적용하였다. 전력분배기 제작 사진은 그림 9 와 같다.

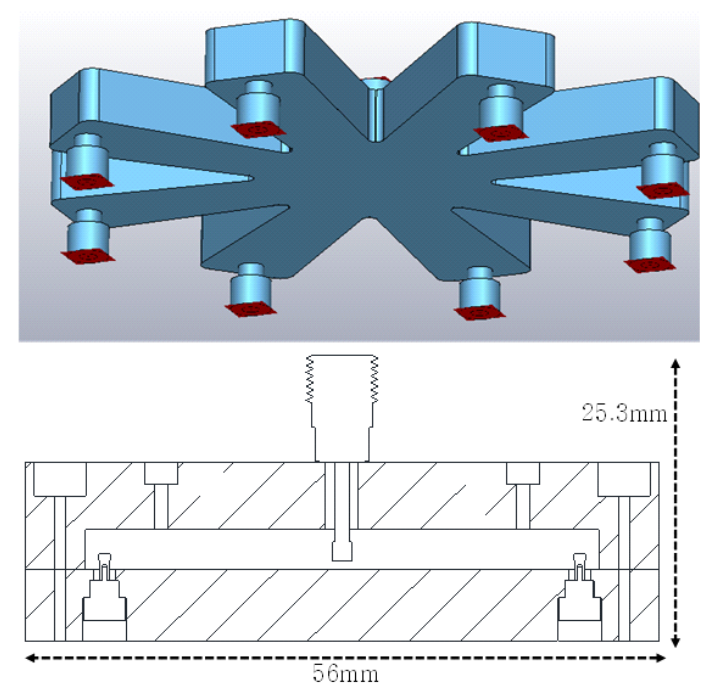

그림 7. 전력분배기 모델링(상) 및 단면(하)

Fig. 7. Modeling(top) and cross section(bottom) of power divider.

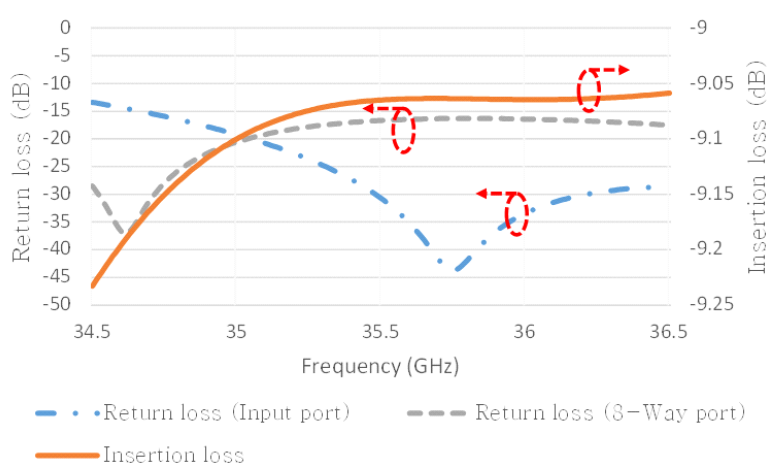

그림 8. 전력분배기 시뮬레이션 결과

Fig. 8. Simulated insertion loss and return loss of power divider.
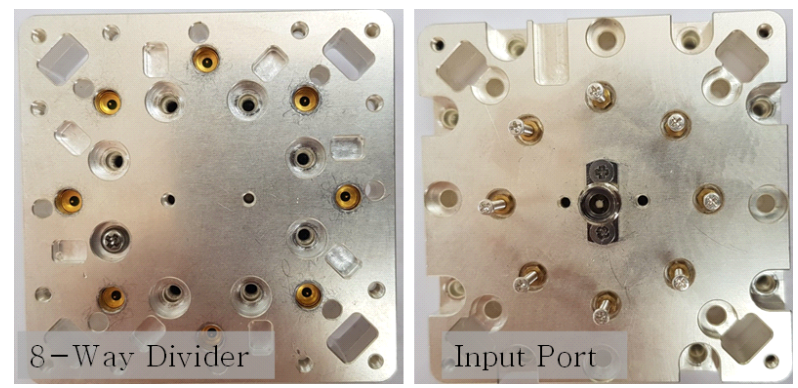

그림 9. 전력분배기 제작 사진

Fig. 9. Photograph of the power divider.

전력결합기는 8 개의 $\mathrm{HPA}$ 모듈 $(10 \mathrm{~W}$ 급)의 전력을 결합 하여 $50 \mathrm{~W}$ 이상의 출력을 내므로 K-커넥터는 정격 전력 이 부족하여 적용할 수 없다.

그리고 Ka-대역 안테나의 입력부는 일반적으로 WR-28 규격의 도파관으로 구성되어 있어 전력결합기의 출력(결 합부)은 WR-28로 설계하였다. 전력결합기는 8개의 SMP 커넥터로 입력을 받아 설계 제작한 프로브를 통해 도파 관으로 전력을 변환하고, 원형의 도파관 구조에 중앙에 있는 프로브를 통해 전력이 결합된다. 이는 다시 동축 형 태로 전력 변환하고, 최종으로 프로브를 통해 WR-28 규 격의 도파관으로 전력 변환한다. 전력을 결합하는 프로브 의 중앙에는 프로브 고정을 위해 테프론을 구성하였고, 중앙 프로브는 황동 재질을 적용하였다. 황동 재질은 베 릴륨동보다 가공이 쉽고, 전기적 특성 차이는 크지 않아 중앙 프로브에 적용하였다. 전력 결합이 되는 프로브는 손실을 최소화하기 위해 일반적으로 사용되는 $2.92 \mathrm{~mm}$ 커넥터의 지름보다 크게 설계하였고, 테프론의 길이를 최 대한 짧게하여 테프론 유전율에 의한 손실을 최소화하였 다. 전력결합기의 모델링 및 단면은 그림 10 과 같고, 높이 는 $29.2 \mathrm{~mm}$ 에 가로/세로 길이는 $56 \mathrm{~mm}$ 이며, 시뮬레이션 결과는 그림 11 과 같다. 시뮬레이션 결과, 삽입 손실은 목 표 대역 내 최대 $-0.1 \mathrm{~dB}(8$-way 분배 손실 $9 \mathrm{~dB}$ 제외)이 고, 입력부 반사 손실은 최대 $-19.21 \mathrm{~dB}$ 이며, 8 -Way 분배 부(출력부)의 반사 손실은 최대 $-20.6 \mathrm{~dB}$ 이고, 전력결합 기 제작 사진은 그림 12 와 같다 ${ }^{[3],[4]}$.

전력분배기와 전력결합기 측정은 단일 모듈로 정확한 특성 확인이 어려워 2개를 백투백(back to back) 구조로 연결하여 측정을 수행하였다. 다만 전력분배기의 경우, 1 

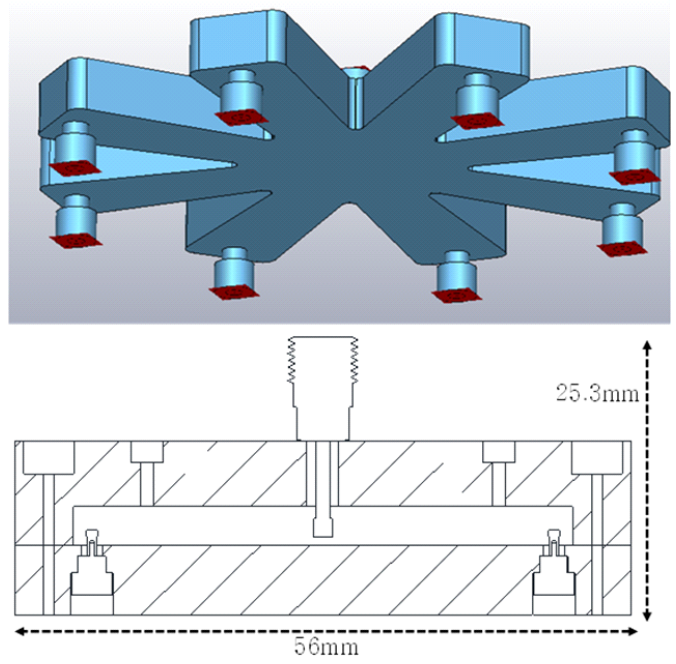

그림 10. 전력결합기 모델링(상) 및 단면(하)

Fig. 10. Modeling(top) and cross section(bottom) of power combiner.

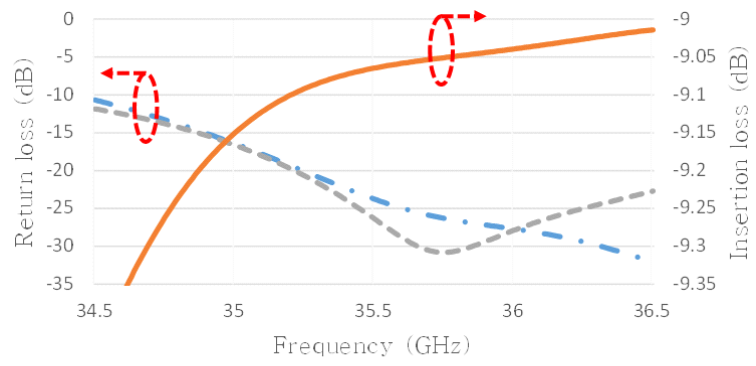

- - Return loss (Combine port) - - - Return loss (8-Way port)

Insertion los:

그림 11. 전력결합기 시뮬레이션 결과

Fig. 11. Simulated insertion loss and return loss of power combiner.
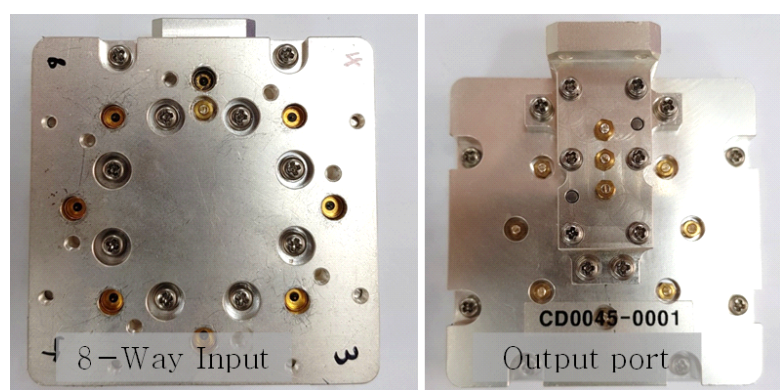

그림 12. 전력결합기 제작 사진

Fig. 12. Photograph of the power combiner.
조만 제작이 되어 전력결합기와 백투백으로 측정하였고, 전력결합기의 백투백 측정 결과를 이용하여 전력분배기 의 특성을 예측하였다.

그림 13은 전력분배기와 전력결합기를 백투백으로 측 정한 결과이고, 그림 14 는 전력결합기 2조를 이용하여 백 투백으로 측정한 결과이다. 백투백으로 측정 시 대역 내 에 공진으로 인한 삽입 손실 증가 및 반사 손실 열화 부 분이 보이는데, 이는 백투백으로 구성하여 구조적으로 나 타나는 것으로 추정하며, SSPA에 체결하여 측정 시 SSPA 송신 출력에 나타나지는 않아서 단품으로는 발생 되지 않는 부분으로 판단된다. 이런 공진 포인트를 무시 하면 전력결합기는 백투백으로 대역 내 최대 삽입 손실 은 $-0.8 \mathrm{~dB}$ 로 전력결합기 한 조의 최대 삽입 손실은

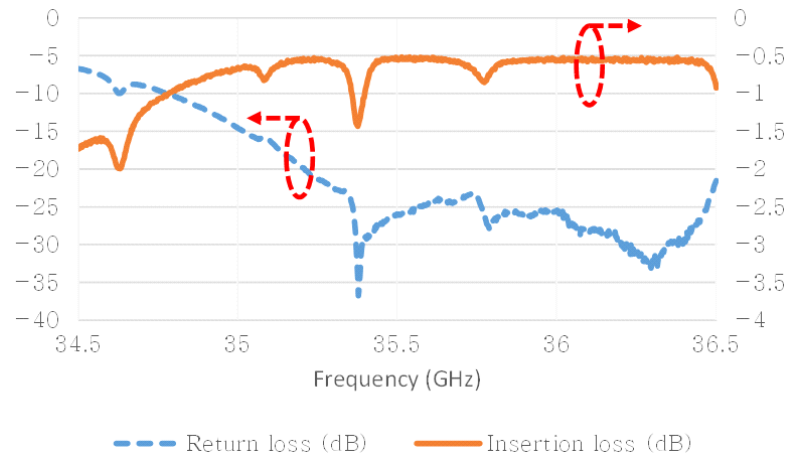

그림 13. 전력분배기-전력결합기 측정 결과(백투백)

Fig. 13. Measured insertion loss and return loss of power divider - power combiner (Back-to-back).

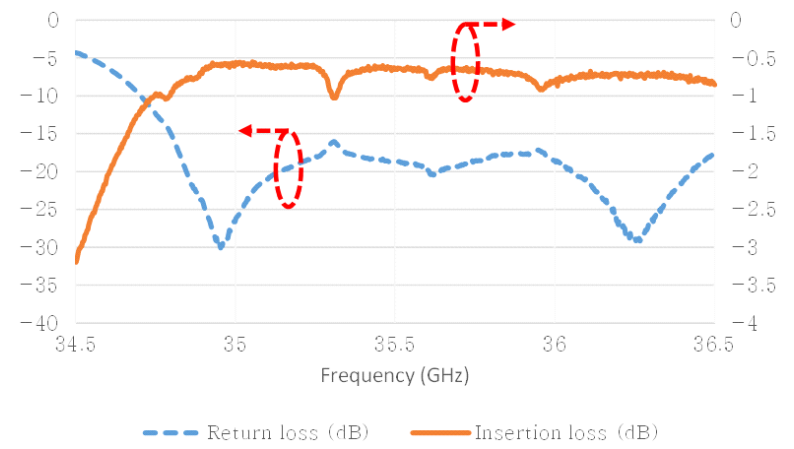

그림 14. 전력결합기 측정 결과(백투백)

Fig. 14. Measured insertion loss and return loss of power combiner (Back-to-back). 
THE JOURNAL OF KOREAN INSTITUTE OF ELECTROMAGNETIC ENGINEERING AND SCIENCE. vol. 32, no. 1, January. 2021.

표 4. Radial 전력결합기 이전 연구와 비교

Table 4. Comparison with some prior radial power combiner.

\begin{tabular}{|c|c|c|c|}
\hline Item & This work & Ref. [5] & Ref. [6] \\
\hline $\begin{array}{c}\text { Frequency } \\
\text { (GHz) }\end{array}$ & $35 \sim 36$ & $29 \sim 31$ & $16.1 \sim 17.2$ \\
\hline $\begin{array}{c}\text { Number of } \\
\text { power } \\
\text { combine }\end{array}$ & 8 & 8 & 16 \\
\hline $\begin{array}{c}\text { Input/output } \\
\text { connector }\end{array}$ & SMP / WR-28 & $\begin{array}{c}\text { K-connector / } \\
\text { K-connector }\end{array}$ & SMA / SMA \\
\hline $\begin{array}{c}\text { Back to back } \\
\text { insertion loss } \\
\text { (measurement) }\end{array}$ & $-0.78 \mathrm{~dB}$ & $-0.67 \mathrm{~dB}$ & $-0.47 \mathrm{~dB}$ \\
\hline $\begin{array}{c}\text { Back to back } \\
\text { return loss } \\
\text { (measurement) }\end{array}$ & $-16.0 \mathrm{~dB}$ & $-20.2 \mathrm{~dB}$ & $-14.1 \mathrm{~dB}$ \\
\hline
\end{tabular}

$-0.4 \mathrm{~dB}$ 이다. 전력분배기의 경우, 전력분배기-전력결합 기백투백 측정과에서 전력결합기의 측정 결과를 빼고 계 산하면 삽입 손실이 $35 \mathrm{GHz}$ 에서 최대 $-0.4 \mathrm{~dB}$ 이고, 평균 $-0.2 \mathrm{~dB}$ 수준이다.

표 4와 같이 기존의 연구와 비교하기에는 주파수와 입 출력 타입이 달라 직접 비교는 어렵지만 ${ }^{[5]}$, 논문과 비교 해 봤을 때, 백투백 기준으로 삽입 손실은 $-0.1 \mathrm{~dB}$ 정도 특성이 나쁘지만 결합부가 WR-28 규격의 도파관으로 변 환하는 구조가 포함되고 주파수가 높은 점을 고려하면 더 우수한 성능을 나타내었다고 판단할 수 있다. 반사 손 실은 참고문헌 [5] 연구가 더 우수하지만, 본 연구의 결과 도 SSPA에 적용하기에는 적합한 수준이다.

\section{2-4 고출력증폭기 시험 결과 (온도 시험 포함)}

고출력증폭기는 신호 발생기로 RF 입력 신호를 인가 하고, 첨두전력계로 출력 레벨을 측정하였다. 송신 출력 은 $35 \mathrm{GHz}$ 에서 최대 $+49.25 \mathrm{dBm}$ 이고, $36 \mathrm{GHz}$ 에서 +48.78 $\mathrm{dBm}$ (최소 $75.5 \mathrm{~W})$ 이며, 듀티는 최대 $20 \%$ 까지 운용 가능 하다. 그림 15 는 주파수별 송신 출력 측정 화면이고, 그 외 항목의 측정 결과는 표 5 와 같다 ${ }^{[5]}$. 논문 대비 효율은 낮게 나타냈지만, 본 연구는 소모 전류에 DC-DC 변환기 를 포함하였고, 이득을 높이기 위한 구동증폭부를 포함하 였다.

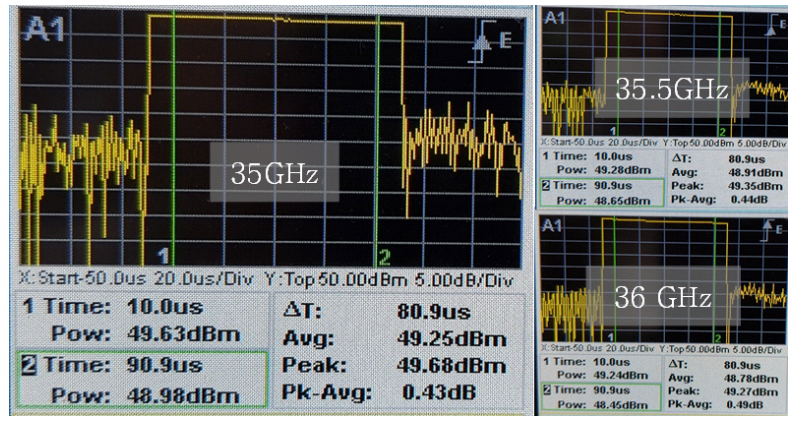

그림 15. SSPA 송신 출력

Fig. 15. Transmit power of The SSPA.

표 5. Ka-대역 고출력증폭기 이전 연구와 비교 Table 5. Comparison with some prior Ka-band SSPA.

\begin{tabular}{|c|c|c|}
\hline Item & This work & Ref. [5] \\
\hline Frequency (GHz) & $35 \sim 36$ & $29 \sim 31$ \\
\hline Output power (dBm) & $48.78 \sim 49.25$ & 44.79 \\
\hline Output power (W) & $75.5 \sim 84.1$ & 30.1 \\
\hline Duty (\%) & 20 & 2 \\
\hline Pulse width (us) & $0.2 \sim 100$ & 4 \\
\hline Pulse droop (dB) & 0.49 & - \\
\hline Linear gain (dB) & 49.0 & 26.4 \\
\hline Efficiency (\%) & $\begin{array}{c}\text { Power consumption } \\
\text { includes DC-DC } \\
\text { convertor and DRA } \\
\text { module }\end{array}$ \\
\hline Remark & \begin{tabular}{l} 
\\
\hline
\end{tabular} \\
\hline
\end{tabular}

고출력증폭기의 방열은 탑재되는 몸체에 전도 방열을 하고, 운용은 5 분까지 하는 것으로 설계하였다. 종단 $\mathrm{HPA}$ 모듈은 방열 특성을 높이기 위해 하우징을 $\mathrm{CuW}$ 로 제작하였다. 고출력증폭기 모델링은 $3 \mathrm{~kg}$ 의 알루미늄 하 우징에 고정되어 있는 형상으로 시뮬레이션을 수행하였 다. 시뮬레이션 결과, 상온에서 5 분 진행했을 때 $\mathrm{HPA}$ 바 닥면은 최고 77.27 도까지 나왔고, 하우징은 70 도이며, 구 동증폭모듈 $\mathrm{HPA}$ 의 바닥면 온도는 75.17도로 나타내었다. 그림 16 은 고출력증폭기의 열해석 시뮬레이션 결과이고, 그림 17은 고출력증폭기 온도 시험 사진 및 결과이다. 온 도 시험은 종단 HPA 모듈의 온도 센서를 이용하여 온도 를 측정하였고, HPA 모듈의 온도 센서는 하우징 바닥면 


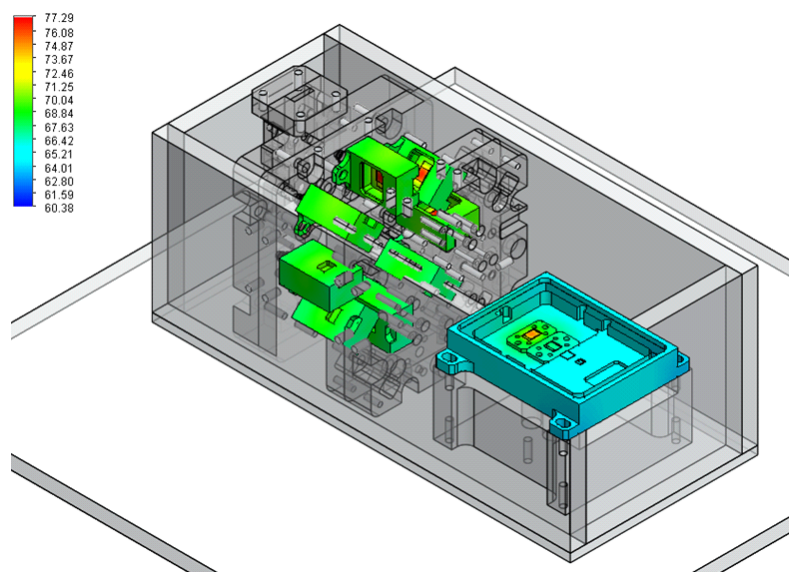

그림 16. 고출력증폭기 열해석 시뮬레이션 결과

Fig.16. Simulated result of thermal analysis for SSPA.

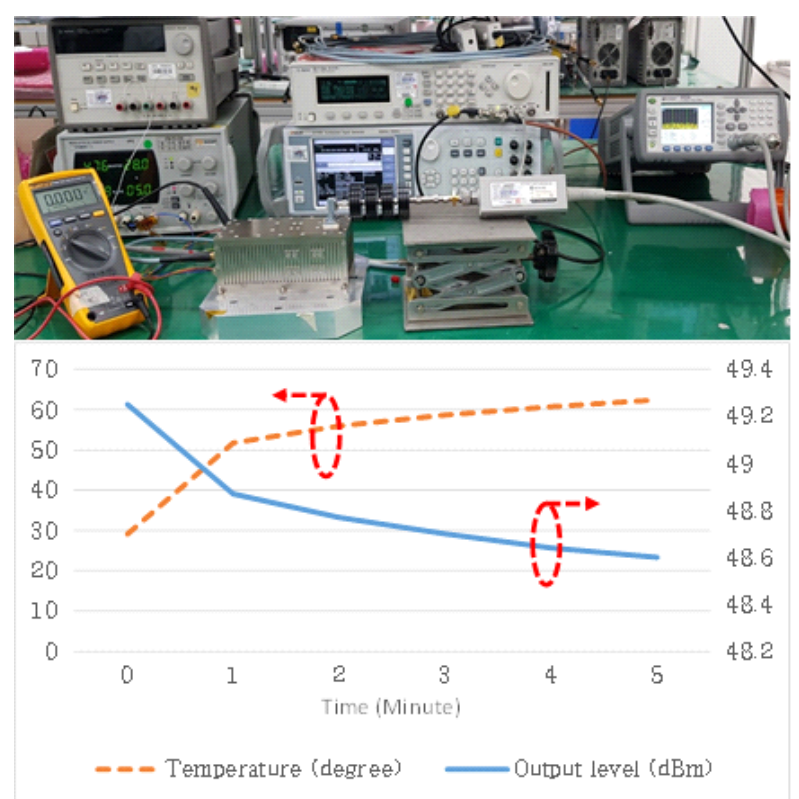

그림 17. 고출력증폭기 온도 시험 사진 및 시험 결과

Fig. 17. Photograph of thermal test and the measured results of SSPA.

에 접촉되어 있다. 주파수 $35 \mathrm{GHz}$ 의 $\mathrm{RF}$ 신호를 인가하여 5 분 운용 온도 시험 결과, HPA 모듈 바닥면의 온도는 최 고 62.4 도까지 상승하였다. 송신 출력은 최초 +49.25 $\mathrm{dBm}(84.1 \mathrm{~W})$ 에서 $+48.6 \mathrm{dBm}(72.4 \mathrm{~W})$ 까지 낮아졌다.

시뮬레이션 결과보다 실제 온도가 낮게 측정되었는데, 이는 시뮬레이션의 발열량은 데이터시트상의 값으로 적

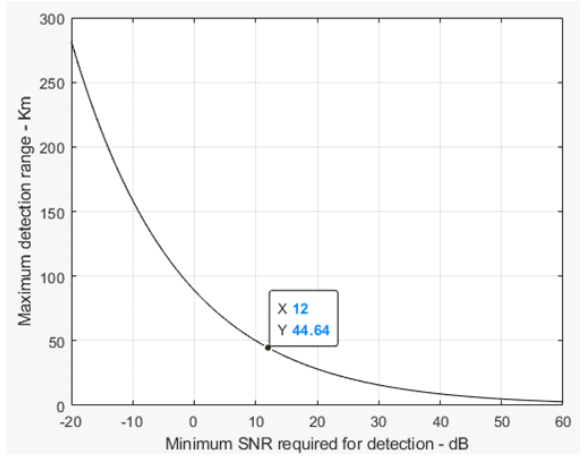

그림 18. 탐지에 필요한 최소 $\mathrm{SNR}$ 대 최대 탐지 거리

Fig. 18. Minimum SNR VS maximum detection range required for detection.

용하였고, 실제 발열은 이보다 적어서 시험 결과상 온도 가 더 낮게 측정되었으며, 그림 17 은 시험 사진 및 시험 결과이다.

본 연구의 $\mathrm{SSPA}$ 를 레이다에 적용하였을 때 식 (1)을 이용하여 탐지거리를 예측하면 $44.64 \mathrm{~km}$ 까지 탐지가 가 능하다. 여기서, $P_{t}$ 는 송신 출력 $(72.4 \mathrm{~W}), \tau$ 는 펄스폭 $(10$ $\mathrm{us}), f_{r}$ 은 펄스 반복 주파수 $(10,000 \mathrm{kHz}), T_{i}$ 는 드웰 간격(1 초), $G_{t}$ 는 송신 안테나 이득 $(35 \mathrm{~dB}), G_{r}$ 은 수신 안테나 이 득 $(35 \mathrm{~dB}), \lambda$ 는 파장 $(8.45 \mathrm{~mm}), \sigma$ 는 타겟 단면적 $\left(1 \mathrm{~m}^{2}\right), \mathrm{k}$ 는 볼츠만 상수 $\left(1.38 \times 10^{-23),} T_{e}\right.$ 는 유효 잡음 온도 $(300 \mathrm{~K})$, $F$ 는 시스템 잡음 지수 $(5 \mathrm{~dB}), L$ 은 전체 시스템 손실 $(5$ $\mathrm{dB}),(\mathrm{SNR})_{\mathrm{O}}$ 는 최소 신호대 잡음비 $(12 \mathrm{~dB}), R$ 은 탐지 거리 $(\mathrm{km})$ 를 의미한다. 그림 18 은 탐지에 필요한 최소 $\mathrm{SNR}$ 대 최대 탐지거리를 나타낸다[7].

$$
R=\left(\frac{P_{t} \tau f_{r} T_{i} G_{t} G_{r} \lambda^{2} \sigma}{(4 \pi)^{3} k T_{e} F L(S N R)_{0}}\right)^{\frac{1}{4}}
$$

\section{III. 결 론}

본 논문에서는 $\mathrm{Ka}$ 대역 $(35 \sim 35 \mathrm{GHz})$ 레이다, 탐색기 및 위성 탑재용 SAR에 적용 가능한 $\mathrm{SSPA}$ 를 설계 및 제작하 였다. $10 \mathrm{~W}$ 급 $\mathrm{GaN} \mathrm{HPA} \mathrm{상용품을} \mathrm{이용하여} \mathrm{단위} \mathrm{전력} \mathrm{증}$ 폭모듈을 제작하였고, 증폭 모듈 출력 결합을 위해 도파 관 형태의 8-Way Radial 결합기를 이용하여 $70 \mathrm{~W}$ 이상의 $\mathrm{SSPA}$ 를 개발하였다. SSPA는 DC-DC 변환기 및 구동증폭 
THE JOURNAL OF KOREAN INSTITUTE OF ELECTROMAGNETIC ENGINEERING AND SCIENCE. vol. 32, no. 1, January. 2021.

부를 포함하고, 전력결합기는 백투백으로 측정한 결과, 삽입 손실은 대역 내에서 $-0.78 \mathrm{~dB}$ 이하이다(결합기 1 개 의 결과는 $-0.39 \mathrm{~dB}$ 이다.). 운용 대역 내에서 송신 듀티 $20 \%$ 까지 동작이 가능하고, 송신 출력은 최대 $84 \mathrm{~W}$ 이다. 냉각장치 없이 상온에서 5 분 운용 시 $72 \mathrm{~W}$ 수준으로 출 력을 나타냈고, 종단 $\mathrm{HPA}$ 모듈의 온도는 63도 이하이다. 종단 $\mathrm{HPA}$ 모듈은 $\mathrm{MMIC}$ 바닥면의 온도를 낮추기 위해 열전도율이 높은 $\mathrm{CuW}$ 를 하우징에 적용하였다.

본 연구를 통해 $\mathrm{Ka}-$ 대역 $(35 \sim 36 \mathrm{GHz}) 50 \mathrm{~W}$ 이상의 $\mathrm{SSPA}$ 제작이 가능함을 확인하였고, 단일 증폭 $\mathrm{MMIC}$ 의 출력 레벨 향상과 결합기의 결합수 및 정격 전력을 향상 시키는 연구를 수행하면 $100 \mathrm{~W}$ 이상의 SSPA 개발이 가능 할 것이라고 기대된다.

\section{References}

[1] P. Jia, "A 2 to $20 \mathrm{GHz}$ high power amplifier using spatial power combining techniques," Microwave Journal, vol. 48, no. 4, pp. 108-113, Apr. 2005.

[2] J. W. Gewartowski, H. A. Watson, Principle of Electron Tubes, New York, NY, D. Van Nostran Company, 1966.

\section{한 재 섭 [LIG넥스원(주)/수석연구원]}

https://orcid.org/0000-0002-4410-6240

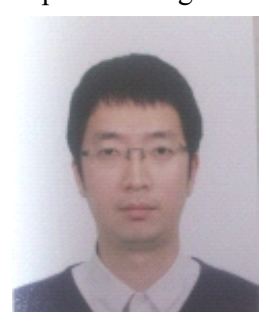

2005년 2월: 숭실대학교 정보통신공학과 (공학사)

2004년 12월 2007년 4월: LG.Philips LCD 엔지니어

2007년 10월 현재: LIG넥스원(주) 수석 연구원

[주 관심분야] 레이다 시스템, $\mathrm{RF} \mathrm{H/W}$ 등
[3] M. Ghanadi, A New Compact Broadband Radial Power Combiner, Berlin, Universitätsbibliothek der Technischen Universität Berlin, 2012.

[4] K. Song, F. Zhang, S. Hu, and Y. Fan, "Ku-band 200-W pulsed power amplifier based on waveguide spatially power-combining technique for industrial appliciations," IEEE Transactions on Industrial Electronics, vol. 61, no. 8, pp. 4274-428, Aug. 2014.

[5] Y. R. Choi, J. W. Lee, S. H. Lee, S. H. An, M. H. Lee, and H. R. Kim, "Development of the Ka-band 20 watt SSPA(Solid State Power Amplifier) using a spatial combiner," The Journal of The Institute of Internet, Broadcasting and Communication, vol. 19, no. 1, pp. 231-238, Feb. 2019.

[6] S. H. Yoon, S. O. Kim, S. H. Lee, B. O. Lim, B. H. Lee, and Y. K. Jeon, et al., "A study on a Ku-band high power and high efficiency radial combiner," The Journal of Korean Institute of Electromagnetic Engineering and Science, vol. 28, no. 5, pp. 400-409, May 2017.

[7] B. R. Mahafza, RADAR Signal Analysis and Processing using MATLAB, Boca Raton, FL, CRC Press, 2009.

$$
\text { 정 주 용 [LIG넥스원(주)/수석연구원] }
$$

https://orcid.org/0000-0003-1221-173X

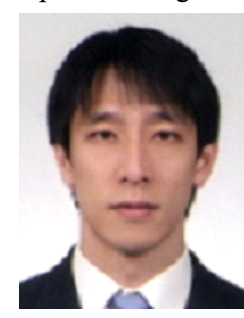

구원
2004년 2월: 연세대학교 전기전자공학과 (공학사)

2006년 2월: 연세대학교 전기전자공학과 (공학석사)

2006년 2월 2007년 4월: 삼성전자 무선 사업부

2007년 5월 현재: LIG넥스원(주) 수석연

[주 관심분야] 위성시스템, 영상레이다, RF 회로, $\mathrm{MMIC}$ 
박 성 민 [LIG넥스원(주)/선임연구원]

https://orcid.org/0000-0002-9353-417X

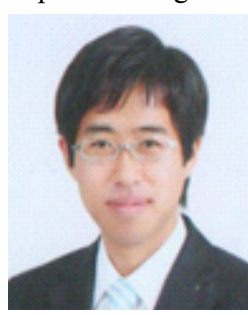

2009년 2월: 홍익대학교 전자전기공학부 (공학사)

2011년 2월: 홍익대학교 전자정보통신공 학과 (공학석사)

2011년 1월 현재: LIG넥스원(주) 선임연 구원

[주 관심분야] 전파 산란, 마이크로파 원 격탐사, SAR 시스템

유 경 덕 [LIG넥스원(주)/수석연구원]

https://orcid.org/0000-0003-2202-5287

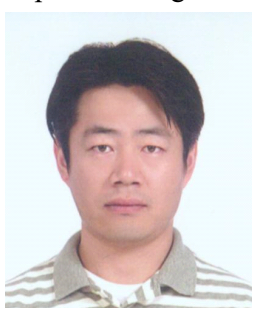

2001년 8월: 한국기술교육대학교 정보통 신학과 (공학사)

2005년 8월: 아주대학교 전자공학과 (공학 석사)

2005년 8월 2010년10월: 엘지전자 $\mathrm{MC}$ 사 업부

2010년 4월 현재: LIG넥스원(주) 수석연 구원

[주 관심분야] 위성시스템, 영상레이다
김 보 균 [유텔(주)/선임연구원]

https://orcid.org/0000-0001-7215-9991

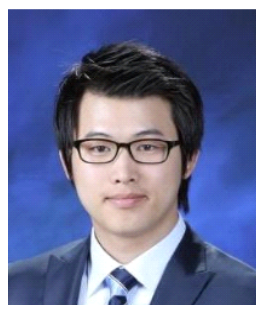

2011년 2월: 순천향대학교 전기통신공학 과 (공학사)

2011년 1월 현재: (주)유텔연구소 선임연 구원

[주 관심분야] RF Power Amplifier, Microwave Active Circuit and Wireless Communication 등
김 효 철 [성산전자/선임연구원]

https://orcid.org/0000-0003-4265-3993

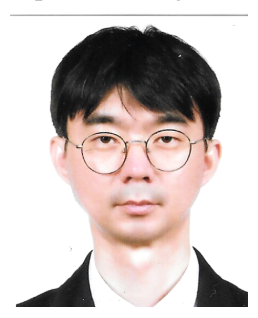

2007년 2월: 제주대학교 통신공학과 (공학 사)

2007년 1월 2008년 3월: 액티패스(주) 연 구원

2008년 3월 2017년 4월 : 이너트론(주) 선임연구원

연구원

2017년 4월 현재: 성산전자통신(주) 선임

[주 관심분야] Cavity Filter, Spatial Combiner, Radial Combiner, Waveguide 